\title{
Discurso artístico y educación estética
}

\section{Artistic discourse and aesthetic education}

\author{
Éder García Dusán*
}

Recibido: 28 de febrero de 2013 / Aceptado: 22 de marzo de 2013

\section{Resumen}

Inscrito dentro de las problemáticas de la educación y la investigación, el objetivo que persigo en este artículo es plantear que uno de los caminos para el desarrollo de una posible educación estética desciende de la puesta en marcha de un modelo de análisis discursivo sobre texturas llamadas performance artísticas y expresiones similares. En estas circunstancias, y partiendo de la tesis de que las expresiones artísticas, como cualquier uso lingüístico, son simultáneamente constitutivas y constituidas tanto de las identidades sociales, en un primer momento especificaré las cualidades comunes y relaciones tanto del tipo de sujeto receptor de estas texturas, como de esta forma particular de arte, para luego proponer un modelo que permita leer sus productos con sentido(s). Posteriormente, para aportar a la validez de tal modelo, lo ilustraré con la experiencia performática "Los BMR (Bamba, Martillo y Refilón)", presentada por el artista Fabio Melecio Palacios en 2011. El artículo concluye con una discusión en torno a dos ideas: i) la ruptura de los límites entre cotidianidad y productos simbólicos creativos y, ii) el valor investigativo que tiene el análisis de texturas artísticas para una educación estética.

Palabras clave: performance art, identidad social, educación estética, análisis discursivo, exclusión social.

\section{Abstract}

Inscribed within the problematic of the education and investigation, the purpose I am following in this reflection is to establish that one of the ways to the development of a possible aesthetic education descends from the implementation of a discursive analysis model about textures called artistic performance and similar expressions. In these circumstances, and based on the premise that artistic expressions, like any linguistic practice are simultaneously both constitutive and constituted not only social identities, first of all, I will specify the common qualities and relations not only on the kind of subject receiver of these textures but also the particular form of this art, and then to propose a model that allows us to read their products with meaning(s). Next, to contribute to the validity of this model, I will illustrate with the performative experience "Los BMR (Bamba, Martillo y Refilón)" by the artist Fabio Melecio Palacios in 2011. The paper concludes with a discussion around two ideas: i) the breakdown of the limits between everyday life and creative symbolic products and, ii) the investigative value that has the artistic texture for an aesthetic education.

Key words: performance art, social identity, aesthetic education, discourse analysis, social exclusion.

\section{Introducción}

En nuestros sistemas formativos, la educación artística tiende a ser considerada como área marginal y, por lo general, es desfavorecida frente a los saberes científico-técnicos, debido a los mitos que rodean el arte y al artista en el contexto de la modernidad, $y$ que son producto de la dicotomía entre la razón y lo

\footnotetext{
* Filósofo graduado de la Universidad Nacional de Colombia. Magister de Lingüística Española del Instituto Caro y Cuervo (seminario Andrés Bello). Hace parte del Consejo Superior de Investigaciones Científicas (CSIC) y del Instituto de la Lengua Española (ILE). Actualmente trabaja en la Maestría en Pedagogía de la Lengua Materna, de la Universidad Distrital Francisco José de Caldas. Pertenece al grupo de investigación Lenguaje, cultura e Identidad. Ha publicado varios artículos en revistas nacionales e internacionales y es autor de dos libros sobre Lingüística teórica y comprensión textual. Correo electrónico: edgardus@hotmail.com.
} 
imaginario, o entre la razón y lo sensible (Jiménez, 2011). Esto ha venido generando prejuicios escolares como que las prácticas artísticas son diferentes a las que se necesitan en la producción o comprensión textuales o que las artes solo se asocian con la creatividad, mientras que las ciencias duras están directamente asociadas a la resolución de problemas a través de métodos rigurosos (Giráldez, 2007), y esto a pesar de que la filosofía alemana moderna ya había demostrado que, en una lucha cara a cara entre ciencia y arte, este último se llevaba la victoria (Nietzsche, 2004) ${ }^{1}$. Más allá de todo esto, permanece la idea que aquellas habilidades atribuidas a la educación artística queda relegada al imaginario del sujeto irreverente y bohemio que se inspira, gracias a que cuenta con tiempo de ocio y que la enseñanza de lo artístico y de la estética no auxilian la formación de ciudadanos críticos sino, a lo sumo, anárquicos y contestatarios; todo esto, a pesar que la Unesco (2006) afirma que la reflexión sobre el arte contribuye a desarrollar facultades físicas, intelectuales y creativas.

No obstante a esta realidad de la escuela, lo cierto es que un discurso artístico es aquel que permite el dialogismo, la reflexión y la crítica frente a aspectos culturales, el cual cae en experiencias emocionales y las sensaciones, al tiempo que las fuerzas que las producen son contrapuestas a la organización en el campo de la educación artística. Según la invitación del profesor Jairo Montoya Gómez, es posible leer las experiencias discursivas artísticas actuales mediante su reconocimiento como "escrituras de las sociabilidades" que se entrecruzan y se convierten en una de las formas de significar la experiencia colectiva actual y donde caben: performances, happening, installations, body art, ready made, land art, reality show, etc. En efecto, para Montoya (2001) tales escrituras son "registros y marcas con los cuales se construyen los espacios de sociabilidad" (p. 81), meros reflejos simbólicos de los modos de vida (ethos) de los sujetos y, por extensión, de su identidad cultural.

Sin duda, se trata de una mirada que logra una significación funcional de las nuevas/viejas formas de estar juntos, pero cifrada en aquellos proyectos contemporáneos que, bajo las premisas del arte actual (del arte desregulado), resemantizan y reterritorializan el espacio cotidiano y sus usos sociales, para dejar ver las formas o pro-formas de la Urbs frente a la Polis ${ }^{3}$, privilegiando así lo impetuoso, la imaginación y la emocionalidad sobre lo racional y lo predecible. Y, para eso, todas estas puestas en escena, paralelas al Estado-nación, resultan ser:

[...] mutaciones aceleradas de los escenarios de lo público que han visto transformar sus anclajes físicos y sobre todo re-configurar estas nuevas arenas públicas en las cuales se pone en escena la publicidad de lo urbano: vaciados de contenidos éticoprácticos, estos lugares reterritorializados, presentan, exponen y exhiben esa gama de intercambios móviles y fugaces que terminan por configurar el universo complejo de sociabilidades. (Montoya, 2001, p. 97)

Esto hace pensar inmediatamente que, dado que cualquier uso de lo simbólico, como es el caso de los discursos artísticos contemporáneos, es al tiempo constituido y constitutivo de las identidades de una sociedad y de sus almacenes de saberes culturales (Fairclough, 2008), todas estas locuciones del arte van dirigidas a las mentes de receptores inmersos en un ambiente tecnificado que ha venido fundando sujetos con un complejo perfil, y que algunos sociólogos y pedago-

1 Afirma Nietzsche (2004): "aquel impulso hacia la formación de metáforas, aquel impulso fundamental del hombre [...] busca un nuevo ámbito para su obrar, y lo encuentra en el mito, y en general, en el arte. Constantemente trastorna las rúbricas y celdas de los conceptos, al instaurar nuevas transposiciones, metáforas, metonimias, constantemente muestra el ansia de configurar el mundo, haciendo de él algo tan colorido, irregular, inconsecuente, inconexo, tan encantador y eternamente nuevo, como lo es el mundo del sueño" (p. 24).

2 Se entiende por Urbs los espacios colectivos produciéndose; un constante hacerse como formas urbanas territorializadas, contrario a una autoridad fiscalizadora o Polis (Delgado, 1999). 
gos han querido llamar generación @ (Feixa, 2005) o nativos digitales (Prensky, 2010). Estos son forjadores y vasallos del mundo iconosférico o protovisual, definidos por ser sujetos con nuevas estrategias cognitivas, además de fabricantes compulsivos de texturas híbridas altamente estéticas (sensibles) y generosamente veladas en redes de signos sofisticadas; además de ser sujetos que se involucran en sus actos productivos, siendo así responsables de sus expectativas de conocimiento, de su información y de sus opiniones, dentro de comunidades abiertas de usuarios reutilizadores que, por la obligatoriedad de sus mismos dinamismos y canales de comunicación, manipulan nuevas representaciones de su realidad social para generar tramas significativas del mundo que moran. Es gracias a esto que se encuentran valoraciones como estas:

La sociedad de la imagen cambió profundamente el sentido y el concepto de representación. Estas dejaron de ser ilustraciones, espejos, imitaciones, y escenificaciones necesariamente presenciales, para dar lugar a la simulación, a la escena virtual y aún a la espectacularización de la vida cotidiana, porque los relatos y las historias se incorporan a los medios de comunicación y porque la dramatización de la vida rompe con las fronteras de lo que antes estaba destinado solo a los escenarios o a la pintura. (Jiménez, 2011, p. 14)

Es así como, ante las nuevas formas de producir discursividades artísticas donde prima la inmediatez, lo fragmentado y la resignificación de la territorialidad, nos encontramos con sujetos-otros que las engendran, promueven y las toman como pretexto para su discurrir.

Lo que entraría en juego aquí es el lugar de una educación estética en el reinado de esas transformaciones culturales innegables, entendiendo por educación estética la enseñabilidad posible que desarrolle y fortalezca "la capacidad de interpretación de la realidad desde la sensibilidad" (Arnaiz, 2008, p. 12). He aquí el puente de la relación decisiva entre los discursos artísticos y la educación estética significativa, puesto que es la sensibilidad o percepción sensible la parte fundamental de la experiencia estética; entonces, no se asume la educabilidad desde claves biologicistas, sino psicologistas. Para entender mejor esto, Umberto Eco (1992) sostiene que la sensopercepción funciona como un principio psicológico de arreglo o convenio donde el sujeto, frente a un estímulo actual, activa («arrastra») el recuerdo de sus pasadas percepciones. De esta suerte, el significado atribuido al texto artístico percibido es el producto de la interacción del stock del usuario (de sus saberes previos, si se quiere) con los rastros que deja esa experiencia actual en su fisiología compleja, abierta y dinámica. Ese significado es, así, una secuela significativo con un presupuesto de entrada; a saber, la aparición de una emoción que dispararía el deseo de dar reducir la tensión que dispara el texto artístico percibido, para luego relajar la práctica voluntaria, arrancando de ella un sentido para obtener de ella un conocimiento:

[...] frente al estímulo originario, el sujeto interviene arrastrando en la percepción actual el recuerdo de sus pasadas percepciones, y sólo así concurre a dar forma a la experiencia en acto; la experiencia que no se limita así a señalar una Gestalt prexistente como autónoma configuración de lo real (y tampoco es, hablando en términos idealistas, un acto libre nuestro de posición del objeto), sino que aparece como el resultado situacional de nuestra inherencia en el proceso del mundo, pero el mundo como resultado final de esta inherencia activa. (Eco, 1992, p. 50)

Pues bien, si se concibe así la educación estética, solo habría que buscar caminos (métodos) para poder visibilizarla en el aula, dada su innegable función como texto de la cultura que, al lado de otros y con igual estatus, contribuye a la formación del pensamiento crítico en la enseñabilidad posible. Para contribuir a esta empresa así delineada pretendo, en adelante, dar cuenta de las cualidades tanto del vigente sujeto que acude a la escuela, como de esas formas actuales 
de fundar experiencias artísticas y su relación con una educación estética para luego, con base en esa doble caracterización, proponer un modelo de intervención comprensiva sobre discursos performáticos, acompañado de un ejemplo local, para evidenciar su validez interna frente a la invitación metódica.

\section{El web-actor: el nuevo sujeto del mundo educativo}

Ahora bien, estas acciones en los lugares de la Urbs actualmente apuntan a un tipo de sujeto que, debido a los progresos info-comuncacionales (redes tecnológicas), puede ser entendido como un homo integrata. No es gratuito que se hable del homo zapping (Le Diberder y Coste-Cerdan, 1990), pues es evidente la capacidad del hombre actual para procesar información de manera hipertextual, lo cual hace que la lógica de la secuencia y de un orden único pierda efectividad (zapear es, en últimas, romper la linealidad con el que se accedía otrora al conocimiento); pero también del homo videns (Sartori, 1998), pues lo visual es lo que ahora domina; y esto al lado del homo estheticus, donde sobresale el hedonismo de lo cotidiano manifestado en el placer de los sentidos, el juego de las formas, la intromisión de lo frívolo en la vida diaria y el camino de la identificación, no de la identidad (Maffesoli, 2007).

En una palabra, propongo hablar de web-actores, ${ }^{3}$ esto es, de sujetos hipermediatizados e hipermediales que, dentro de comunidades inteligentes propias de la Web 2.0, crean, hacen circular y manipulan diariamente procesos u objetos que encierran relaciones fragmentadas y emergentes, y que generan productos textuales con matices enteramente novedosos como el entrecruzamiento de tramas causadas por la abundancia de microredes sociales que se entretejen cada vez con nuevas y transitorias alianzas entre actantes y objetos, además de la presencia de la indexicalidad mediata, la ironía, la parodia y el montaje de muchas variables coexistiendo con una exigencia de relacionalidad fortuita, a la manera de capas comunicantes o cajas chinas. Dadas estas condiciones, muy al contrario de quienes satanizan estas nuevas coordenadas de producción textual (Carr, 2011), en lugar de menguar la concentración y la abstracción del usuario, más bien le exige despertar habilidades cognitivas como la usanza de procesamientos tanto seriales como paralelas, además de la estimulación de nuevas sinapsis en la resolución de acertijos multivariables y conflictos:

Es posible que los productos de la cultura de masas ahora no sean más que un infierno de inmoralidad y degradación, en cualquier sector; pero seguro que cada día son más complejos y diversos, ricos en retos para la mente, capaces de desarrollar nuestro deseo innato de resolver problemas y no de narcotizar las neuronas con un entorno carente de estímulos. En una palabra: inteligentes. (Wu Ming 2, 2007, p. 109)

En estas circunstancias, la comprensión de la información, valorada como dinámica, inmediata y solidaria, resulta contigua a una lógica discursiva del zapping. En efecto, los esquemas mentales de las multitudes sociales de web-actores son estimulados y reconstruidos más por un método alusivo a lo pasajero y fragmentado, que por la "fábula" aristotélica de la pedagogía atenida al guion y sustentada en la linealidad discursiva:

Como es bien sabido, el zapping es un ejercicio que los receptores hacen, mitad muestra de insatisfacción y ansiedad, mitad de rebeldía contra la programación. De acuerdo con él, un receptor más nervioso e impaciente que el tradicional, cambia permanentemente de estímulo buscando algo que

3 Con este neologismo se desea resaltar el hecho del dinamismo y protagonismo de los productores actuales (actores), lo mismo que el hecho de que sus texturas circulan en un nuevo canal comunicativo que, por cierto, permite no sólo el desarrollo de las inteligencias colectivas, sino la democratización y el perfeccionamiento pragmático de sus productos, gracias al dialogismo inmediatista que permiten la NTIC (Web). 
lo satisfaga o simplemente llame su atención [...] [haciendo que los discursos empiecen a] convertirse en géneros confusos que todo lo mezclan y combinan con el fin de fijar a la audiencia ante propuestas omniabarcadoras, confeccionadas con lenguajes altamente seductores y livianos, compuestos discursivos híbridos en los que todo se junta. (Urresti, 2008, p. 25)

Pero, y he aquí lo interesante, el homo zapping se completa con el homo videns en paisajes étnicoculturales fluidos y cambiantes, pues estas generaciones son dependientes de la televisión (ejemplo privilegiado del mundo iconosférico), medio que justamente ha revolucionado las formas de comunicación y ha intervenido en la manera tradicional de construir el pensamiento, modificándolo radicalmente, pues se traslada del texto de la palabra al texto de la imagen; desplazamiento nada inocente que obliga a ajustar nuevos modos de percepción de la cotidianidad con experiencias fugaces, y a pasar de lo lógico y su exigencia de entendimiento racional a su captura inmediata y afectiva en texturas predominantemente analógicas.

Ahora, al ser toda captura simbólica de la realidad del orden de lo fragmentario y lo afectivo, el homo zapping-videns también es, ante todo, un sujeto que establece juegos para poder significar su realidad, al punto que ha hecho de la cultura misma su juego; en suma, un homo ludens, pues el juego es, principalmente, el conjunto de las manifestaciones humanas irracionales relacionadas con los mitos y sus intercambios comunicativos. Aún más, "la existencia del juego corrobora constantemente, y en el sentido más alto, el carácter supra-lógico de nuestra situación en el cosmos" (Huizinga, 1990, p. 14).

Efectivamente la realidad de las texturas actuales patentiza que los nuevos códigos de la Web 2.0 están henchidos de imágenes que relevan estructuras de carácter más global, pero también más dependiente de los saberes previos comunes de los interlocutores que lo usan en sus comunicaciones, así como también menos dependientes de las reglas fijas de las gramáticas públicas y tradicionales (Woodfield, 1993). Esto es palpable en el caso de la comunicación por messenger, que remplaza descripciones regidas por leyes acusativo-nominativas por un emoticono, haciendo que no solo se produzca una renovación sintáctico-semántica, cada vez más transmutada por la rapidez y la limitación de caracteres (mini-mensajería celular o Twitter), sino que también privilegian un nuevo orbe pragmático, cuya intencionalidad fundamental es la trasmisión de emociones y afectos inmediatistos, en textos de enunciación fundamentalmente amorosos y expresivos, como se deja ver en las rutinas de la red social Facebook. Por esto que es posible hablar de nacionalismos emocráticos, donde prima una especie de cogito interruptus actuando desde los fundamentos de una pasión estética basada en energías tan intensas como perecederas.

Un buen ejemplo de esto último fue la forma cómo los jóvenes construyeron la realidad política de Antanas Mockus en la contienda electoral efectuada en Colombia en 2010. Como se sabe, después de ser un aspirante más en el abanico de candidatos, por su particular forma de simbolizar su idea básica de antipolítico forjando política, pasó a ser el principal antagonista de Juan Manuel Santos, apoyado por aquella comunicación dotada de poder y agenciada por multitudes juveniles desde varios grupos y aplicaciones en Facebook, donde el uso céntrico del signo visual (v. gr., girasol, lápiz, color verde, posaderas del propio Mockus), además de glosolalias hipersensibles (meras transliteraciones de nanas infantiles), complementadas por pequeñas carnestolendas en plazas públicas y ciclovías, permitieron expresar con saltos y esparcimientos grupales una emocionalidad politizada y que fueron el remplazo de un discurso con contundencia, claridad de ideas y estrategias argumentativas basadas en lo real de la situación del país. Fue así como, tras las propuestas emotivas respaldadas por estructuras icónicas sacadas de la cotidianidad con gran hechizo y acreditadas por más de 
tres millones de seguidores seducidos, esto es, por una muchedumbre de hommo emo-videns-ludens en plena acción comunicativa, creativa y solidaria, se creó y se mantuvo esa fe pasajera y fragmentaria de un mandatario filósofo para Colombia: un mundo ficticio masificado en red que esperó poco tiempo para entrar en "la peste del olvido" macondiano. (García-Dussán, 2011). ${ }^{4}$

\section{Performance art: las novedosas formas de producir arte}

Performance art, también llamado Acontecimiento, Accion art, Fluxus (fluir) o, por otros investigadores, Happening (evento), es un tipo de arte que realiza una acción en el transcurso de la cual se mezclan o se unifican diferentes tipos de sistemas artísticos (danza, música, teatro, actuación espontánea, etc.) y diferentes tipos de sensaciones (visuales, auditivas, gustativas, corporales, etc.), por lo cual es, de alguna forma, un arte zappeado e interdiscursivo, pues cada cambio de estímulo y cada mixtura entre ellos, crea esta lógica. Su característica principal es demandar la participación abierta del espectador, como sucede en la Web 2.0, tratando de reflejar simbólicamente nuevas formas de sociabilidad bajo el método del palimpsesto, y que termina revelando la coexistencia de variables de diferentes espacios y tiempos en un mismo escenario, a la vez que crea gramáticas de la contingencia, ajustadas sobre lo icónico y lo indicial (Pezo, 2005).

Bajo estas circunstancias, lo que prima en este tipo de arte es la espontaneidad clarividente, sin acatar a sus efectos. Por eso que se dice que es una experiencia fugaz. En estas circunstancias, la escenificación de la acción simplemente sucede:

Lo efíemro marca su intrascendencia, la libertad de actuación es su norma. Con guión o no, ensayado o improvisado, en grupo o en solitario, con efectos visuales, lumínicos y musicales, este arte de acción requiere de un espectador distinto, abierto a nuevas posibilidades sensibles [...] Al público se le impone recomponer los fragmentos lanzados como figuras dispersas, interpretar los múltiples sentidos que integran este rompecabezas. (Fajardo, 2006, p. 63)

Aunque comparta el mismo significante con la performance propuesta en la Escuela de Oxford (J. Austin), su sentido es diferente, pues en las puestas en escena, a diferencia de la performance lingüística que intenta mover a un cambio mediante del discurso, el acto o el actor solo acontece. Es decir, algo o "alguien aparece de pronto", en un sobresalto; y su acción no opera, simplemente es. No presenta ilocuciones definidas, no tiene como objetivo ni siquiera la producción de la catarsis porque los actos no producen éxtasis; el sujeto ya no sale de sí porque él mismo actúa ya como no-sujeto (des-anudado), como nosí-mismo: simplemente está abstraído, en otro sitio, mientras recorre estéticamente esos no-lugares de siempre o de repente. El incidente (aquello que sobreviene) o el accidente (el suceso eventual) que ocurre en los espacios museísticos, teatrales o públicos (bar, calle, mall) son, entonces, puestas en escena que se caracterizan por:

1. Necesitar un público y un espacio de operación,

2. Romper la jerarquía entre la acción y su registro,

\footnotetext{
4 En efecto, si se parte de la tesis de que tanto los problemas sociales como las representaciones de ciudadanos se crean y controlan a través de discursos cuyo canal privilegiado son las Nuevas Tecnologías de la Información y la Comunicación (NTIC), se entiende cómo la re-creación virtual del entonces candidato presidencial, se gestó gracias a los eventos dinamizados en redes sociales como Facebook y Twitter. El análisis sintáctico y semántico-pragmático de los constituyentes de este evento permite releer, por un lado, la relación política-emoción en el marco conductual de la Web 2.0 y, por otro, las formas cómo las multitudes juveniles ejecutan su poder desde canales más afines a sus expectativas para formar ensueños colectivos, vigorizar cambios de opinión y construir significaciones sociales.
} 
3. Avanzar sin intenciones pre-definidas, esperando que las complete o infiere el espectador,

4. Dejar que suceda, en directo, de forma abierta y sin intermediarios;

5. Poseer tramas inferenciales que no siempre son visibles y claras, por lo que exigen, tras la sorpresa y la ambigüedad, la autoreflexión.

Obsérvese cómo estas son características espaciales, vivenciales y conductuales propias de aquel anónimo urbanita que transita presuroso por la calle, por el sistema de transporte, por el centro comercial, por el museo, el parque o la plaza; pero también por las redes sociales propias de la red. Así las cosas, el sujeto se desplaza de la Polis a la Urbs hasta hacer del territorio un espacio-paso (¿espaso?) y él mismo alguien que pasa por allí, haciendo muchas veces de punto o aglomeración, necesario solo para configurar una nube de sujetos, tan súbita como contingente.

En estas circunstancias, el observador queda atrapado por lo fugaz del artista, está-ahí "como si no estuviera" a la espera de lo inesperado como un verdadero "animalito público", viviendo en un nicho confuso y dotado de órganos sensoriales complejos que le permiten estar inmerso en un juego de respuestas condicionadas culturalmente, mientras el escenario de ese animal es la ciudad múltiple evolucionada y fantasmal (Delgado, 1999). En suma, espacio acuoso que soporta sujetos en éxtasis y, una vez enganchados al evento, vagabundean movidos por su pulsión de vida. He aquí un rasgo interesante que está en la base de la posición del observador de este tipo de arte: la activación de su pulsión erótica, de su carga emocional cardinal, de su impulso para no dejar de ver y oír. En inglés pulsión es drive, en alemán, trieb. $\mathrm{Y}$ de trieb-drive en francés y español: dérive-deriva. Llamar, entonces, a la deriva la acción del auditorio es empezar a hablar del sujeto de la pulsión: sujeto atri(e)bulado. Como se suele decir coloquialmente, para que este tipo de rituales de paso enmarcados en las acciones performáticas no se escape de la mente del espectador, este debe estar preparado para este tipo de texturas con el ojo clínico y el olfato afinado; solo así puede sentir visceralmente de qué le habla el texto estético y qué tanto le afecta cuando le dice algo.

Ahora bien, como se puede asociar claramente, las características de cualquier experiencia estética coincide con las producciones que manipulan y re-crean desde diferentes ángulos los llamados webactores, pues tanto textos performáticos como textos hipermediales están acoplados sobre alianzas textuales $^{5}$, (indexicalidad, avenencia de variables, iconicidad, gramáticas visuales, etc.). Si esto está bien pensado, se abre la posibilidad de hacer dialogar en el aula de clase las nuevas texturas dentro de los nuevos sujetos, de la cual he dicho que exige la autoreflexión dada su condición ambigua de mostrarse y de reflejar la realidad. Así las cosas, la pregunta que se forja es ¿dentro del contexto educativo actual, invadido de la capa social de nativos digitales, cómo crear un puente metodológico, que permita intervenir textos performáticos en la educación estética?

\section{Arquitectura de un modelo para leer sistemas artísticos}

Una manera de aproximarse analíticamente a este tipo de experiencias artísticas para aprovecharlas como parte de un programa de educación estética que sea tanto un complemento de la formación lectora de la realidad social, como una salida alternativa al asunto de las bajas competencias lectoras que se presentan en las pruebas nacionales e internacionales del país, es inscribiéndolas como usos lingüísticos

6 Con esto, me refiero a la miscelánea de gestualidad, habla, las imágenes, escritura, objetos tridimensionales, colores, música, olores, sabores, sonidos no convencionales, entre otros modos de expresión. 
multimodales y también como modos de acción que, estando situados sociohistóricamente, constituyen la realidad social, al tiempo que son constituidos por aquella. Esto es lo que, en términos del profesor de la Universidad de Lancaster Norman Fairclough, podemos llamar discurso. Ahora, los discursos se actualizan gracias a ciertos órdenes. Un orden del discurso es "una configuración estructurada de prácticas discursivas, asociada con un espacio social de extensión variable" (Fairclough, 1998, p. 51). En otras palabras, los discursos son sistemas formales y socialmente transformadores del que dispone la gente para recrear e interpretar relaciones, identidades $y$ saberes sociales mediante la convivencia simultánea de inclusión/exclusión, oposición/acuerdo, de discursividades (charla, actuación, exposición, entrevista, silencio, reprimenda, acción cotidiana, etc.). Pero, y he aquí algo preñado de consecuencias, esas prácticas discursivas y sus armonías hacen parte de prácticas sociales; de suerte que:

La conexión entre texto y práctica social se considera mediada por la práctica discursiva: por una parte, los procesos de producción e interpretación textual son conformados por ( $y$, a su vez, ayudan a conformar) la naturaleza de la práctica social, y, por otra, el proceso de producción conforma (y deja "rastros") en el texto, y el proceso interpretativo opera sobre la base de las "señales" del texto. (Fairclough, 2008, p. 4)

A partir de este marco social y analítico del discurso, es posible determinar, al menos estos tres niveles de intervención reflexiva sobre los discursos (usos lingüístico y social, conectados por sus condiciones de producción-interpretación), permitiendo pensar en un modelo que se concentre en revisar tanto la forma como la función de sus tejidos dentro de los juegos comunicativos al reconocer lo lingüístico de la emisión, los procesos de comprensión y producción de ideas y los entornos sociales que vienen a dar cuenta de las interacciones y su situacionalidad. Dicho de otra forma: "a) el uso del lenguaje, b) la comunicación de creencias (cognición) y c) la inte- racción en situaciones de índole social" (Van Dijk, 2000a, p. 23); es decir, reconoce tanto lo textual como lo sociocognitivo y lo contextual, lo que nos interesa justamente aquí, dado que lenguaje y cultura se alimentan mutuamente.

Ahora bien, para el estudio del primer nivel, el del uso lingüístico -o simplemente el del texto-, es importante anotar la noción de estructura compleja, dinámica y estructurada por niveles. Van Dijk, por ejemplo, hace notar que, esta esencia teorética de los discursos "son el resultado de análisis teóricos y, en consecuencia, puede variar considerablemente en diferentes enfoques" (2000b, p. 253). Aquí el mismo autor recuerda que esa estructura y sus estrategias relevantes van desde lo paralingüístico, pasando por lo morfológico (estilística léxica), lo sintáctico (variación en el orden o en las relaciones jerárquicas de las cláusulas y oraciones, con el uso de los pronombres, etc.), la semántica (relación entre estructura superficial y profunda) y las formas cómo se anudan en coherencias locales y globales, hasta llegar a todos aquellos fenómenos pragmáticos, sumados a estructuras retóricas; sumando, además el uso del vocabulario, los modos y las modalidades.

Como es sabido, en cada una de estas dimensiones o niveles, ya previstos esencialmente por Benveniste, el discurso va dejando huellas que marcan propósitos e ideologías que van sumando a la unidad completa del discurso. Ahora bien, tratando de constituir un esbozo para determinar esas relaciones estructurales de los discursos performáticos y su análisis orgánico, se puede pensar en tres grandes niveles: el de la sintaxis, que deja notar el material simbólico sintagmático de un discurso, y donde suele predominar la cronosintaxis o la toposintaxis; el de los significados, producto de la unión de varios semas en campos que abre gradual y progresivamente cada discurso, y, finalmente, el del nivel pragmático, donde se expresan las relaciones de los significados y sus sentidos con el contexto sociohistórico y cultural que activa el usuario del discurso. Desde 
el tratamiento de ese cuadro estructural-funcional, se destila una interpretación, intentando cualificar su intencionalidad social y donde su explicitación auxilia la construcción de hipótesis de sentido con alcance inferencial/crítico (García-Dussán, 2008). En otros términos, se revisa el código, objeto de estudio, desde niveles básicos de ordenamiento o sintaxis, para ir descubriendo los significados de esas combinaciones, hasta lograr entrever el uso de esos elementos combinados en determinados contextos sociales e históricos mediante macro-estrategias retóricas, argumentativas, y de mecanismos de inferencialidad ${ }^{6}$.

En el caso de los textos performáticos, sus elementos constitutivos básicos son los actantes, que desarrollan las acciones en espacios y tiempos concretos, los cuales están encuadrados en acciones determinadas, aunque efímeras y espontáneas la mayor de las veces; todo esto por el transcurrir de la narración multimodal. En este nivel de análisis se determina la forma cómo las acciones se tejen a partir de los sujetos y objetos comprometidos, acompañando su reconstrucción con el auxilio de otras claves semióticas (música, gestos, símbolos, etc.), y visuales (el uso cromático de los ambientes, etc.), como preparación para su proceso en el siguiente nivel, el de la combinación. Sin duda, este primer momento de intervención no sobrepasa la intención del avance de una re-construcción literal del sistema que desmiembra de la unidad holística de detalles objetuales, actanciales y crono-tópicos, quedando así reveladas las unidades-base de las acciones nucleares y su forma de trenzarse en su despliegue satelital.

En el segundo momento, el centro del «lenguaje artístico» no se establece y sedimenta en el nivel de lo literal o denotativo, sino en el de lo asociado. La connotación está aclimatada en los más difusos procedimientos de las estructuras de producción/com- prensión de los sistemas de creencias y estereotipos que alimentan la vida sociocultural de un colectivo humano. Así las cosas, la denotación monosémica emergería como una vuelta hacia el interior del lenguaje, mientras que la connotación polisémica sería un mecanismo de obra abierta, trascendente hacia la sociedad y la cultura. Para elaborar la significancia que de allí se puede desglosar, el productor de estos sistemas se vale de muchas figuras retóricas enclavadas entre los hilos del tejido, tales como los movimientos semánticos-clave o ciertos símbolos cotidianos que exigen ser decodificados esmeradamente a la luz de su evolución polisémica y contextual de sentido. Aquí es frecuente el uso de ciertas estratagemas como las descritas en la tabla 1:

Todo esto sugiere deslizarse desde una capa o cara del tejido sistémico hacia la otra (la patente o disfrazada). En este sentido, la representación performática estaría cualificada por esta dimensión doble; gracias a lo cual se inaugura la posibilidad de concebirse como un mensaje estético, es decir, como un conjunto sígnico «ambiguo y autorreflexivo» (Eco, 1986, p. 122).

Bajo este tipo de esfuerzos, el receptor-lector inicia un momento de interpretación, donde trata de conferir sentido a partir de de-codificaciones parciales; vale decir, un sujeto que supera el análisis primario, pero no se sustrae de él, como cuando se llega a la proposición habiendo maniobrado anteriormente la oración. Ahora, en esa acción, es fundamental, como en cualquier análisis, la pericia de la asociación y el pronóstico controlado para pasar de los significados a los sentidos, lo cual reenvía el significado de los códigos a los efectos connotativos y, de allí, a los saberes socioculturales o al mundo de la vida, porque, para producir sentido(s), el sujeto debe:

6 En este contexto, comprendo por capacidad inferencial el conjunto de proposiciones agregadas que generalizan, elaboran, reordenan o conectan el texto original y que se disparan gracias a la atención de palabras, generalizaciones, detecciones macroestructurales, activación de saberes extra o inter textuales, doxas, etc. (Pipkin, 2002). 
Tabla 1. Categorías de análisis del segundo momento

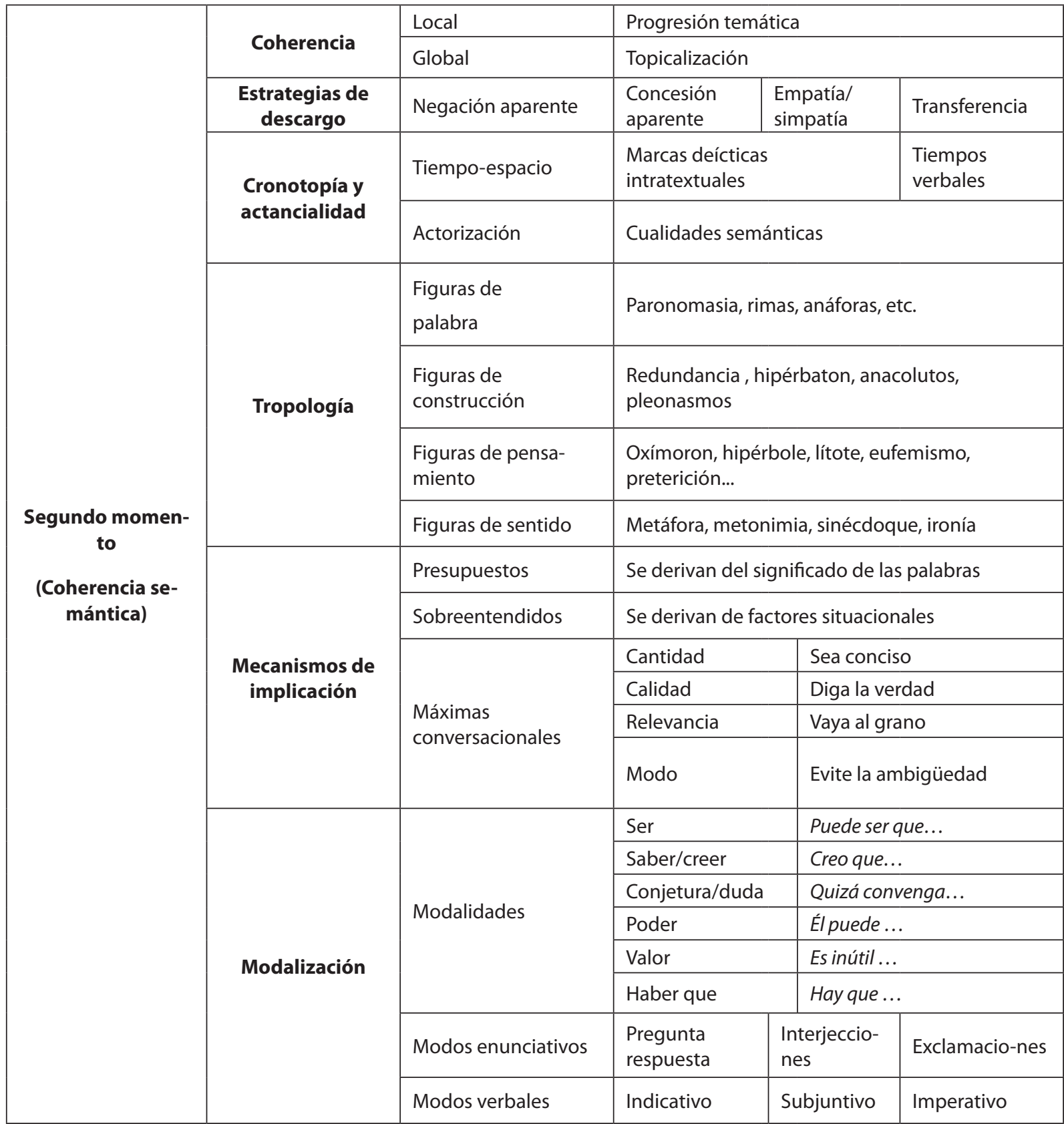

Fuente: elaboración propia

[...] reducir la incertidumbre desde la cual se aborda el texto; para ello debe atender las relaciones literales y no literales, implícitas y explícitas, paradigmáticas y sintagmáticas, textuales y contextuales, desde las cuales se alimentan las diferentes facetas, porque leer es diálogo abierto o semiosis infinita, que (...) activa marcos de conocimiento y descubre infinitos efectos connotativos, los cuales deben ser leídos de manera coherente a la luz de cierta teoría, conocimiento o saber cultural. (Cárdenas, 2006, p. 298) 
Finalmente, se avanza hacia el trabajo del nivel del uso social, donde cobran un sentido fundamental la recuperación del contexto de enunciación y la lectura dialógica de los sentidos con datos propios de las prácticas históricas heredadas y metas sociales. En términos de Fairclough (2008): "El análisis del evento discursivo como práctica social puede referirse a diferentes niveles de organización social - el contexto de situación, el contexto institucional y el contexto social más amplio o 'contexto de cultura”' (p. 6). Aquí, el lector determina un sentido completo por medio de inferencias intratextuales e inter-textuales y se exige una conclusión en el marco de una lectura que involucra claves historiográficas, culturales y personales. Se reitera, entonces, que los sentidos que despliega un discurso están en el juego asociativo de lo textual con los simbolismos, imaginarios, saberes, ideologías y valores (opiniones, estereotipos y prejuicios), y que, al ser trabajados, obliga a un proceso en el que entran en diálogo reflexivo los saberes del lector, los del texto y los imaginarios colectivos que circulan en diferentes épocas históricas. Para este nivel, suele ser importante el reconocimiento de, al menos, las siguientes categorías:

Tabla 2. Categorías de análisis del tercer momento

\begin{tabular}{|c|c|c|c|}
\hline \multirow{18}{*}{$\begin{array}{l}\text { Tercer nivel o del uso } \\
\text { social }\end{array}$} & \multirow{5}{*}{$\begin{array}{l}\text { Esquemas } \\
\text { textuales }\end{array}$} & Narrativo & Quépasa \\
\hline & & Descriptivo & Qué-cómo es $X$ \\
\hline & & Argumentativo & Qué pienso \\
\hline & & Explicativo & Por qué es así \\
\hline & & Dialogal & Qué dicen \\
\hline & \multirow{5}{*}{$\begin{array}{l}\text { Intención o fun- } \\
\text { ción social }\end{array}$} & Veredictivas & $\begin{array}{l}\text { Absolver, condenar, valorar, describir, diagnosticar, } \\
\text { estimar, medir, caracterizar... }\end{array}$ \\
\hline & & Ejercitativas & $\begin{array}{l}\text { Nombrar para un cargo, destituir, mandar, ordenar, } \\
\text { avisar, rogar, aconsejar, vetar, promulgar, perdonar, } \\
\text { recomendar... }\end{array}$ \\
\hline & & Compromisorias & $\begin{array}{l}\text { Prometer, proponerse, hacer voto de, jurar, dar la } \\
\text { palabra de, apoyar, oponerse, declarar la intención... }\end{array}$ \\
\hline & & Comportativas & $\begin{array}{l}\text { Dar las gracias, dar el pésame, felicitar, criticar, quejar- } \\
\text { se, desear, maldecir, bendecir, brindar, desafiar... }\end{array}$ \\
\hline & & Expositivas & Afirmar, negar, enunciar, subrayar, responder... \\
\hline & \multirow{4}{*}{ Intertextualidad } & Cita & Un patatexto (PT) se incorpora al texto... \\
\hline & & Alusión & Mención al PT \\
\hline & & Estilización & Referencia el modo de enfocar el tema propio del PT \\
\hline & & Criptopolémica & Presencia reflejada de un PT en el T \\
\hline & \multirow{4}{*}{$\begin{array}{l}\text { Puntos internos de } \\
\text { vista }\end{array}$} & Homodiegético & A la vez que narra, participa en las acciones \\
\hline & & Autodiegético & Siendo héroe, narra su propia historia \\
\hline & & Paradiegético & Es un actor testigo, padeciendo la historia \\
\hline & & Metadiegético & Es personaje de la historia, pero narra una segunda \\
\hline
\end{tabular}

Continúa en la siguiente página 


\begin{tabular}{|c|c|c|c|}
\hline Estereotipos & \multicolumn{2}{|c|}{$\begin{array}{l}\text { Imagen o idea aceptada } \\
\text { comúnmente por un grupo con carácter } \\
\text { inmutable }\end{array}$} & $\begin{array}{l}\text { De género, de clases sociales, } \\
\text { raciales, políticos, sobre el físico... }\end{array}$ \\
\hline \multirow{5}{*}{$\begin{array}{l}\text { Operaciones ideo- } \\
\text { lógicas }\end{array}$} & Legitimación & \multicolumn{2}{|c|}{ Racionalización, universalización.. } \\
\hline & Simulación & \multicolumn{2}{|c|}{ Sustitución, eufemización, tropos } \\
\hline & Unificación & \multicolumn{2}{|c|}{ Estandarización, simbolización de unidad } \\
\hline & Fragmentación & \multicolumn{2}{|c|}{ Diferenciación, expurgación del otro } \\
\hline & Cosificación & \multicolumn{2}{|c|}{ Naturalización, nominalización/pasivización } \\
\hline $\begin{array}{l}\text { Opiniones y pre- } \\
\text { juicios }\end{array}$ & \multicolumn{3}{|c|}{$\begin{array}{l}\text { Creencias /doxa/: formación de un concepto o juicio sobre alguien o algo de } \\
\text { forma anticipada, sin realmente conocerlo: sexismo, tribalismo... }\end{array}$} \\
\hline $\begin{array}{l}\text { Simbolismos y } \\
\text { Valores }\end{array}$ & \multicolumn{3}{|c|}{$\begin{array}{l}\text { Cualidades de los sujetos, resultado de la interpretación que hace el sujeto de } \\
\text { la utilidad, deseo, importancia, interés, etc. }\end{array}$} \\
\hline
\end{tabular}

Fuente: elaboración propia.

Resumiendo, se delinea el siguiente camino de intervención, esto es, para una lectura con sentido(s) frente a los sistemas textuales artísticos en general, $y$ performáticos, en particular:

Tabla 3. Modelo de análisis discursivo propuesto para la intervención lectora de sistemas performáticos

\begin{tabular}{|l|l|l|}
\hline Dimensión discursiva & Ámbito & Acción básica de análisis \\
\hline Uso lingüístico & Estructural & $\begin{array}{l}\text { Determinación y relación de las unidades constitutivas del discurso en } \\
\text { términos de actancialidad y cronotopía. }\end{array}$ \\
\hline Práctica discursiva & $\begin{array}{l}\text { Sociocogni- } \\
\text { tivo }\end{array}$ & $\begin{array}{l}\text { Alerta y análisis connotativo de elementos como simbolismos, imagina- } \\
\text { rios, valores, ideologías, intertextos, etc. }\end{array}$ \\
\hline Práctica social & Cultural & $\begin{array}{l}\text { Dialogismo entre los sentidos tejidos inferencialmente y el marco socio } \\
\text { histórico y cultural de enunciación. }\end{array}$ \\
\hline
\end{tabular}

Fuente: elaboración propia.

Una vez esbozado este modelo es importante aclarar que no siempre es fácil separar el segundo momento del tercero propuesto en el modelo, dado que muchas de las connotaciones sobre el material significante del texto artístico atesoran sentido(s) en el marco de ciertos contextos sociohistóricos determinados, haciendo que frecuentemente la combinación o trabajo semántico proyecte elementos que se trabajan en la interpretación y estos, a su vez, ya toman forma y contenido en el empalme con los posibles eventos y sucesos históricos.

\section{La experiencia artística 'los bamba, martillo y refilón (BMR) BMR'}

El 30 de junio de 2011, el artista visual nariñense Fabio Melecio Palacios, egresado del Instituto Departamental de Bellas Artes de Cali, se dio a conocer con la performance "No todo es igual, no todo tiene la misma significación", que fue, por cierto, su tesis de grado, la cual se expuso en el Museo del Banco de la Republica en Cali. Allí centró su interés por poner en tela de juicio los tabúes, los clichés, los prejuicios y la estigmatización social del negro: el malo, el feo, el bárbaro, el indeseable. Para mostrar esto, Palacio 
instaló unas fotos de negros marginales y unas grabadoras con audífonos sobre una pared. El público, entonces, escuchaba lo que había en la cinta mientras miraban las fotos y, de acuerdo con propios sus criterios, actualizaban sus deseos inconscientes de rechazo o estima frente al otro; posteriormente las personas que aparecían en las fotos hacían su presencia con la misma apariencia de la imagen, con el fin de que fueran juzgados y estereotipados de acuerdo con su apariencia física (Angola, 2010).

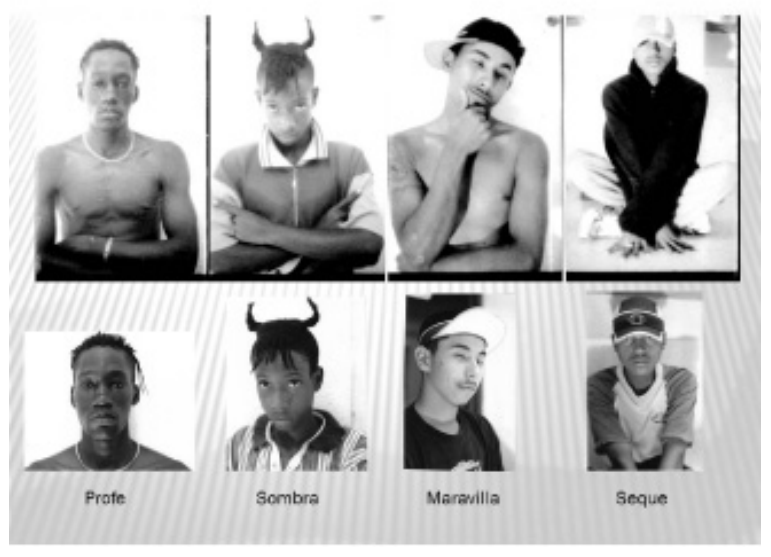

Figura 1. Performance No todo es igual, no todo tiene la misma significación (Palacio, 2001)

Tomado de http://fabiomelecio.blogspot com/2012_07_01_archive.html

Luego pasó por los salones regionales de arte, por el Salón de Octubre y por algunos Festivales de Performance en Cali, hasta que el 30 de junio de 2012, presenta en la Galería Santa Fe su obra 'Los BMR'. Esta experiencia sensible o estética comenzaba por la confusión en torno a la sigla que insinuaba una muestra de prestigiosos y lujosos autos de gama alta (BMW de la casa automotriz germana), pero que guardaba algo diferente, línea de su anterior trabajo. En todo caso, con este experimento, el 16 de diciembre de 2011 ganó la VI versión del Premio Luis Caballero (IDARTES), el galardón más importante de la plástica en el país. ¿Cómo intervenir esta práctica discursiva y qué relación funda con las prácticas sociales nuestras?
Pues bien, aquí basta seguir juiciosamente los parámetros del modelo insinuado. Lo primero, entonces, es describir gruesamente lo que se encuentra a nivel del uso lingüístico. Como se decía atrás, el elemento más notorio del texto por subrayar es el desplazamiento que ofrece el título mismo de la obra: BMW: Bayerische Motoren Werke se resignifica y translitera como BMR: Bamba, Martillo, Refilón. La bamba se refiere a la marca del machete Gavilán Colorào bamba, uno de los más prestigiosos para la labor en los cañaduzales; mientras que el martillo es un machete secundario usado para completar el corte de la planta. Finalmente, el refilón es la mejor técnica para hacer cortes correctos de la caña. Pero, en general, esta experiencia fue la sumatoria de cuatro elementos constitutivos más, subsistiendo mutuamente en el mismo espacio de la galería de arte, a saber:

- Performance de afilado durante la inauguración de la muestra: aquí el padre del artista y dos corteros aguzaron en vivo sus machetes, creando aquel sonido ominoso y torturante del metal contra la piedra.

- Instalación: 582 machetes empleados antiguamente en los cañaduzales y ya desechados por los corteros de caña, fueron cuidadosamente colgados en el techo de una sala de la Galería Santa Fe y que corresponden a los marcas/nombres de machetes bamba, martillo y refilón.

- Un video de las plantaciones de caña de azúcar en el Valle del Cauca.

- La presentación de la indumentaria de trabajo de los obreros de los cañaduzales, ubicados en un extremo de la sala.

- Así las cosas, el texto presenta la siguiente determinación actancial y cronotópica: 
Tabla 4. Determinantes textuales del uso lingüístico Los BMR

\begin{tabular}{|l|l|l|}
\hline \multicolumn{1}{|c|}{ Elementos } & Referencias & \multicolumn{1}{c|}{ Texto Los BMR } \\
\hline \multirow{2}{*}{ Actancialidad } & Yo & $\begin{array}{l}\text { Trabajadores afrodescendientes negros + Herramientas para cor- } \\
\text { tar la caña + Plantaciones de la caña de azúcar. }\end{array}$ \\
\cline { 2 - 3 } & Tú & $\begin{array}{l}\text { Sociedad en general (históricamente caracterizada por la exclu- } \\
\text { sión, la xenofobia y los procesos de blanqueamiento). }\end{array}$ \\
\hline \multirow{2}{*}{ Referencialidad } & Él & $\begin{array}{l}\text { Hay } 582 \text { machetes colgados del techo de una galería, 3 corteros } \\
\text { haciendo su trabajo de afilar sus machetes (B,M,R), mientras un vi- } \\
\text { deo muestra la cotidianidad del obrero (cómo se corta caña y qué } \\
\text { hace el gremio de corteros). }\end{array}$ \\
\hline & Aquí & $\begin{array}{l}\text { Es una re-creación de un cañaveral y sus latifundios, pero de forma } \\
\text { invertida, donde prima la labor silenciosa y dispendiosa de las jor- } \\
\text { nadas de trabajo de los corteros. Remite al Ingenio Central Castilla, } \\
\text { donde trabajó el padre de Palacios por 15 años. }\end{array}$ \\
\cline { 2 - 3 } & Ahora & \\
\hline
\end{tabular}

Fuente: elaboración propia.

Obsérvese que, como práctica discursiva, el texto de Palacio privilegia un indicio, la presencia de los machetes que, gracias a la semiosis instaurada, son significantes de los cañaduzales (un significante siempre remite a otro). Como sabemos que se trata de un performance, y como toda obra desregulada, pues muestra formas de sociabilidad, es necesario comenzar a madurar la combinación machete-corteros vallecaucanos-sociedad colombiana, silenciado por mucho tiempo, como el silencio en el que desarrolla la acción de afilar y el olvido de la labor del cortero en el trasegar socioeconómico del país. Es así como algunos de los elementos allí instaurados, comienzan a generar connotaciones que impactan directamente y generan simpatías socioculturales mediante la estrategia retórica de la analogía. Entre los más notorios tenemos (tabla 5).

Tabla 5. Elementos de la performance Los BMR como práctica discursiva

\begin{tabular}{|l|l|l|l|}
\hline \multicolumn{1}{|c|}{ Claves } & \multicolumn{1}{|c|}{$\begin{array}{c}\text { Elementos } \\
\text { constitutivos } \\
\text { del texto }\end{array}$} & \multicolumn{1}{|c|}{$\begin{array}{c}\text { Elementos de la irradiación } \\
\text { analógica }\end{array}$} & \multicolumn{1}{c|}{ Connotación/sentido } \\
\hline Título de la obra & BMR & Marca del auto Marca del machete & Identidad social \\
\hline Protagonistas & $\begin{array}{l}\text { Trabajador eficiente de } \\
\text { etnia negra }\end{array}$ & Trabajo Urbano Labor Rural & Eficiencia y éxito \\
\hline $\begin{array}{l}\text { Instrumento de } \\
\text { trabajo }\end{array}$ & Machete & $\begin{array}{l}\text { Vigor del Motor Enjundia de los } \\
\text { machetes Bamba y Martillo }\end{array}$ & $\begin{array}{l}\text { Fuerza y vigor: machete es el } \\
\text { diminutivo de macho }\end{array}$ \\
\hline
\end{tabular}

Fuente: elaboración propia. 
Mientras que cualquier empresario urbano codicia un auto BMW, cualquier negro cortero de caña en el Valle desea el pesado machete Gavilán Colora’o Bamba, dado que con él se hacen cortes más eficientes y este es el presupuesto de su honra y distinción como trabajador dentro de su gremio. Esta preferencia de uno y otro actor social por tales instrumentos de trabajo y que cuidan y consienten con esmero, posee, además, el plus de que ayudan a conformar su identidad personal, la cual, como se sabe, se fragua con ayuda de la marca del auto, del vestido laboral, del color de la piel, del éxito en las tareas públicas, y similares.

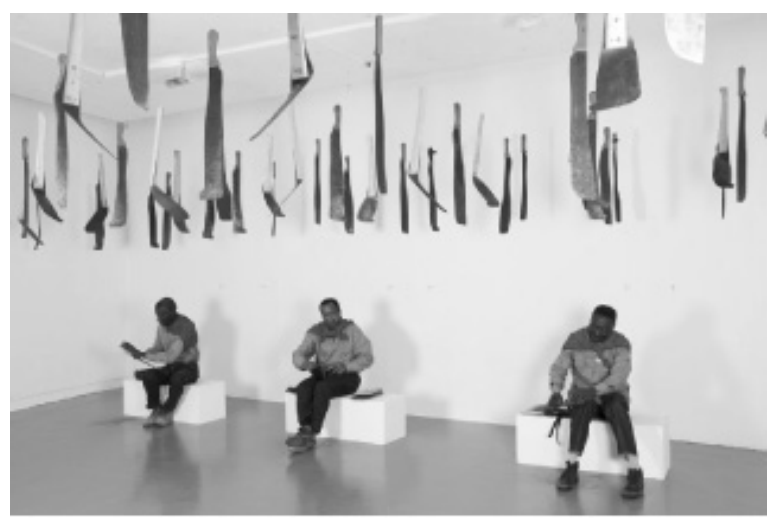

Figura 2. Performance Los BMR (Palacio, 2011). Tomado de: http://www.culturarecreacionydeporte.gov.co/portal/ node/4920

Lo propio del sujeto dentro de nuestras sociedades es, entonces, la reputación del objeto que posee y, por una simple acción metonímica, el trabajador termina identificándose con las cualidades de lo que se dice de su objeto. Así, bajo esta estrategia eficaz, su imagen y su reputación o descalificación frente a los otros queda supeditada por la marca de lo que se tiene y con lo que se hace. Pero estas estratagemas también son constitutivas de identidades sociales, pues el hecho de que del machete se asocie con una violencia primitiva - pero consistente a lo largo de la historia colombiana-, recuerda el conflicto partidista llamado La Violencia (1948-1958), cuyas prác- ticas sociales aún resuenan, tales como la exclusión y la muerte del otro gracias a la identificación de un color representativo de un partido político, donde Chulavitas de Boyacá y Pájaros del Valle de Cauca hicieron atrocidades con auxilio del machete. Pero también evoca irremediablemente las huellas históricas de la lucha racial de una comunidad negra por su supervivencia y dignificación laboral.

Como es sabido, en el Valle del Cauca hay haciendas con cañaduzales y trapiches desde el siglo XIX (v. gr. El Paraíso y María, retratados fielmente en la novela escrita en 1867 por Isaacs) pero es solo hasta de los años cuarenta cuando nace el Ingenio Castilla. Actualmente, el 99.7\% del azúcar que consume Colombia se produce en el Valle del Cauca, departamento donde hay más de 198.000 ha. de caña que ocupan, aproximadamente, el $49 \%$ del total de área sembrada en la región. La mayoría de los corteros de caña son afrocolombianos (cerca de 18.000 en 2008), quienes trabajan entre 10 y 12 horas diarias bajo el sol y la lluvia por sueldos que apenas superan el salario mínimo, lo que les ha obligado a vivir por años en el hacinamiento y la pobreza (Montoya, 2011).

Muchos colombianos conocieron esto por las fugaces noticias sobre los paros de los corteros del Valle del Cauca en protesta por las precarias condiciones laborales (contratación indirecta, inestabilidad laboral, bajos precios en la tonelada de caña recogida, falta de transporte, etc.), como los paros y resistencias de 2005 y 2008, "La huelga de los machetes caídos".

Así las cosas, este texto, más allá de su configuración literal, está disfrazando una intención más de orden político, una denuncia que, partiendo de las mismas víctimas de la injusticia social y con los mismos instrumentos de su identidad colectiva, adelanta una hipercorrección sobre el estigma y la exclusión de la raza negra, teñida de una cierta satanización sobre sus acciones y de hasta su propio 
cuerpo, muchas veces percibido monstruoso e iracundo y representadas en una cierta gramática racial que descalifica al negro al dejarlo ver salvaje y amenazador, tal como lo atestiguan los estudios de Viveros Vigoya (2000). De esta suerte, la performance de Palacio, se sitúa más en esos intentos de romper el silencio (paradójicamente con un silencio aturdidor en la galería, valga el oxímoron), y así dar cuenta de la reconstrucción de la función de la etnia negra: de malo e indeseable a trabajador persistente, sufrido y abnegado; cualidades que también son parte importante en los relatos que permiten la construcción de identidad nacional. A propósito, el mismo Palacio afirmó en su momento que la idea central de su obra BMR era:

Resaltar la labor de los corteros de caña de azúcar, pero haciendo que el espectador sintiera la amenaza y los riesgos permanentes: cortarse, enfrentarse con animales venenosos, cansarse hasta más no poder, tener que seguir haciendo esfuerzos y saber que hay que terminar. (19 de diciembre de 2011)

De hecho, para él mismo fue milagroso ser finalista del Premio Luis Caballero, pues hasta esa versión aparecía el primer artista afro, coincidencialmente en el mismo periodo en el que se celebraba el Año de los Afrodescendientes, declarado por Naciones Unidas en memoria de las víctimas de la esclavitud. Después de recibir su galardón, confesó a la Revista Arcadia: "Cuando tenía 15 años [...] en mi salón sólo había una persona de tez negra que dibujaba. Era yo. Y no se me puede olvidar que un compañero me dijo un día: No hay artistas negros. Vos sos el primero, ¿no?" (Junca, 2012), lo cual hace recordar, ese suceso cuando Bush, antes de ser relegido, visitó al entonces presidente Cardoso del Brasil, y le preguntó con merodeo: "¿Ustedes también tienen negros?"; para luego hablar de los progresos de la humanidad. Todo esto no hace sino ratifica la trascendencia de una estigmatización de los negros, al tiempo que su exotización, desvalorización, colonización y sutil, pero efectiva, eliminación física y simbólica, que tuvo su origen en la Colonia (Viveros y Díaz, 2010).

Y a propósito de coincidencias macabras, en el mismo mes en que fue entregado el premio a Palacio, la revista española Hola, en su edición de diciembre de 2011 (número 3514), publicó un reportaje sobre la mansión de "las mujeres más poderosas del Valle del Cauca", y lo ambientó con una enorme imagen de cuatro refinadas señoras sentadas en amplios sofás blancos con una vista paradisíaca de la ciudad a sus pies. Lo indagador es que la fotografía deja ver entre los sofás y el paisaje, dos mujeres negras, uniformadas de blanco que sostienen bandejas y que están estratégicamente ubicadas como si fueran dos objetos decorativos. Luego, en la página 14, las dos aparecen en la cocina en pose similar a la anterior, mientras desde la página opuesta Sonia Zarzur sonríe mientras luce un collar de perlas. Esto despertó la indignación en muchos colombianos quienes, por las redes sociales, denunciaban el hecho como excluyente, mientras los medios daban cuenta de hechos de segregación racial de los barrios de la ciudad de Cali y la sospechosa escasez de empleos para gente negra en los bancos y supermercados caleños (Rodríguez, 11 de diciembre de 2011).

\section{Conclusiones}

Tras este recorrido es fácil advertir que, tomando como punto de partida el texto performático cuya recepción exige la sensibilidad audiovisual, la tensión cognoscitiva y el repaso emocional, se puede alcanzar a un punto de llegada, una acción que permite el paso de la experiencia estética a la realidad social. Esto no hace sino confirma cómo el arte actual, en cualquiera de sus manifestaciones, parte de la cotidianidad y da cuenta de ella, a la espera que el espectador-lector genere la continuidad entre sus tramas semiodiscursivas y la realidad sociopolítica que contiene de forma cifrada. Es así como se confirma la postura política del arte, como lo ha querido subrayar recientemente el Nobel de literatura Mario 
Vargas Llosa (2003). En nuestro caso, deja ver cómo perviven y persisten los estereotipos y las estigmatizaciones del negro en nuestra cultura y cómo estas sirven de pivote para que se sigan realizando formas sutiles de esclavitud, satanización y exclusión.

Pero el ejercicio no solo confirma ese tipo de creencias y acciones, por cierto, propias de una historia trazada por la xenofobia hacia las minorías étnicas y justificada por políticos y comunidades sociales de elite, incluyendo la ciudad letrada colombiana (recuérdese, verbi gracia, cómo hasta 1982 ser homosexual era delito en Colombia o cómo políticos como Luis López de Mesa o Laureano Gómez sostenían en pleno siglo XX la idea que la mezcla de culturas inferiores [indígenas y negros] generaba productos inadaptables), sino también el valor investigativo que tiene el análisis de texturas artísticas para una educación que, desde la experiencia estética, camino regio y aún poco explorado de forma sistémica en la escuela, fomente la conciencia histórica, la responsabilidad social y el pensamiento crítico.

Vistas así las cosas, la propuesta esbozada no solo sirve para repensar la naturaleza y la función del texto performático, en particular, y de las experiencias artísticas en general, sino para relacionarlas con la revisión discursiva apoyada en sus valores artísticos formales (armonía con la estructura lingüística lo cual posibilita su análisis), sus valores miméticos o de verdad (correspondencia su núcleo pragmático, lo que posibilita su interpretación) y, finalmente, sus valores estéticos o expresivos, que se conectan con las vivencias colectivas y las emocionales de los lectores frente a lo comunicado por el autor(es) de la puesta en escena textural de este nuevo tipo de arte (Piotrowski, 1996).

\section{Reconocimientos}

Este artículo es el resultado de la investigación Textos creativos y la identidad social en Colombia (20132014), adscrita al grupo de investigación Lenguaje, cultura e identidad, de la Universidad Distrital Francisco José de Caldas.

\section{Referencias}

Angola, M. (2010) Una aproximación a las estéticas afrodescendientes en el arte colombiano contemporáneo. En Colombia afrodescendiente. Bogotá: Panamericana.

Arnaiz, V. (2008) El maestro: un visionario y un seductor. La estética su imprescindible. Revista Internacional del Magisterio, (34).

Bogotá lo tiene todo. (19 de diciembre, 2011) Boletín 366. Recuperado el 9 de julio de 2013, de ww.culturarecreacionydeporte.gov.co.

Cárdenas, A. (2006). Para leer mejor. En L. Ramírez y G. Acosta Valencia (Eds.), Estudios del discurso en Colombia 8 (pp. 295-311). Medellín: Sello Editorial Universidad de Medellín.

Carr, N. (2011). Superficiales. Madrid: Taurus.

Delgado, M. (1999). El animal público. Barcelona: Anagrama.

Eco, U. (1986). La estructura ausente. Madrid: Lumen.

Eco, U. (1992). La obra abierta. Buenos Aires: Planeta.

Fairclough, N. (1998). Propuestas para un nuevo programa de investigación del Análisis Crítico del Discurso. En M. Martín y R. Whittaker (Eds.), Poder-decir o el poder de los discursos (pp. 35-54). Madrid: Arrecife.

Fairclough, N. (2008). El Análisis Crítico del Discurso y la mercantilización del discurso público: las universidades (Traducido por Elsa Ghio). En Revista Discurso \& Sociedad, 2(1) 170-185.

Fajardo, C. (2006). El arte en tiempos de globalización. Nuevas preguntas, otras fronteras. Bogotá: Ediciones Unisalle.

Feixa, C. (2005). Generación XX. Teorías sobre la juventud en la era contemporánea. En Revista Latinoamericana de ciencias sociales, niñez y juventud, 4(2), 21-45. 
García-Dussán, É. (2008). Manual de hifología. Análisis e interpretación de textos. Bogotá: Ediciones Unisalle.

García-Dussán, É. (2011). El delirio mockusiano, tecnologías de la comunicación y acción política juvenil. Tendencias y Retos, 16 291-305.

Giraldez, A. (2007). Competencia cultural y artística. Madrid: Alianza.

Huizinga, J. (1990). Homo ludens. Madrid: Alianza.

Jiménez, L. (2011). Arte y ciencia en la educación básica: hacia un nuevo equilibrio entre el saber y el sentir. Revista internacional Magisterio, 49), 16-21.

Le Diberder y Coste-Cerdan. (1990). Romper las Cadenas. Barcelona: Gedisa.

Maffesoli, M. (2007). El crisol de las apariencias: para una ética de la estética. España: Siglo XXI.

Montoya, J. (2001). La escritura del cuerpo/el cuerpo de la escritura. Medellín: Universidad Nacional de Colombia.

Montoya, G. I. (2011). El paro de corteros de caña en el Valle del Cauca - Colombia: Una acción colectiva de cara al modelo económico. Revista Entramado, 7(1), 104-113.

Nietzsche, F. (2004) Sobre la verdad y la mentira en sentido extramoral. Cuadernillo Señal que cabalgamos (42), Año 3.

Trabajadores cañeros de Colombia (2008, 22 de septiembre) Boletín de prensa. Recuperado el 10 de julio de 2013, de http://corteros.blogspot. com/2008_09_01_archive.html.

Junca, H. (2012). Bamba, Martillo y Refilón. Recuperado el 26 de junio de 2013, de http://www. revistaarcadia.com/arte/articulo/bamba-martillo-refilon/27093.

Piotrowski, B. (1996). La literatura: ¿Culto o cultivo de valores? Revista Litterae, 6 5-26.

Pipkin, M. (2002). Diálogo con el texto. En M. Martínez (ed.), Propuesta de intervención pedagógica para la comprensión y producción de textos académicos. Cali: Artes gráficas UniValle.

Pezo, M. (2005). Operaciones instantáneas. Bifurcaciones Revista de estudios culturales urbanos, 3. Bifurcaciones Ltda.

Prensky, M. (2010). Enseñar a nativos digitales. Madrid: Ediciones SM.

Revista Hola (2011, 7 de diciembre). Las mujeres más poderosas del Valle del Cauca 6-14.

Rodríguez, C. (2011, 11 de diciembre). La foto del año (afro). El Espectador, 5.

Sartori, G. (1998). Homo videns. La sociedad teledirigida. Madrid: Taurus.

UNESCO (2006). Hoja de ruta para la educación artística. Conferencia mundial sobre la educación artística: Construir capacidades creativas para el siglo XXI. Unesco, Lisboa, 6-9 de marzo de 2006. Lisboa: Unesco.

Urresti, M. (2008). Ciberculturas juveniles. Buenos Aires: La Crujía.

Van Dijk, T. (2000a). El estudio del discurso. En T. Van Dijk (Comp.). El discurso como estructura y proceso. Barcelona: Gedisa.

Van Dijk, T. (2000b.) Ideología. Una aproximación interdisciplinaria. Barcelona: Gedisa.

Vargas, M. (2003). Literatura y política. Madrid: FCE.

Viveros, M. (2000). Dionisios negros. En M. Figueroa y P. Sanmiguel (Eds.). ¿Mestizo Yo? Bogotá: CES, U.N.

Viveros, M. y Díaz M. (2010). Raza, sexualidad y la colonización de los cuerpos en Colombia. Colombia afrodescendiente. Ministerio de Educación Nacional. Documentos No. 12. Bogotá: Panamericana.

Woodfield, S. (1993). Psicología ordinaria y ciencias cognitivas. Barcelona: Gedisa.

Wu Ming 1\&2 (2007). Mitología, épica y creación pop en tiempos de la red. Revista Archipiélago, 77-78. 